\title{
Quantifying the Bicycle Share Gender Gap
}

Kate Hosford, Meghan Winters ${ }^{\dagger}$

Keywords: equity, gender, bicycling, bicycle share

https://doi.org/10.32866/10802

\section{Transport Findings}

\begin{abstract}
In this paper we examine the gender split in 76,981,561 bicycle share trips made from 2014-2018 for three of the largest public bicycle share programs in the U.S.: Bluebikes (Boston), Citi Bike (New York), and Divvy Bikes (Chicago). Overall, women made only one-quarter of all bicycle share trips from 2014-2018. The proportion of trips made by women increased over time for Citi Bike from 22.6\% in 2014 to $25.5 \%$ in 2018, but hovered steady around $25 \%$ for Bluebikes and Divvy Bikes. Across programs, the gender gap was wider for older bicycle share users.
\end{abstract}

\section{RESEARCH QUESTION AND HYPOTHESIS}

There remains a sizeable gender gap in bicycling in US cities (Dill et al. 2014; Pucher et al. 2011; Singleton and Goddard 2016; Schoner, Lindsey, and Levinson 2014). According to the American Community Survey (ACS), women make up less than a third (28\%) of commuters who regularly bicycle to work in the United States (U.S.Census Bureau 2017). The ACS data provide some indication of the gender gap in bicycling but detailed data on the frequency of bicycle trips is more difficult to obtain.

Bicycle share system data is a relatively new source that can offer insight into the frequency of trips made by men and women. Some have proposed that bicycle share programs may serve to narrow the gender gap by normalizing the image of bicycling as an everyday activity (Goodman, Green, and Woodcock 2014). Analyses of bicycle share system data can provide insight into whether the gender gap in bicycling is changing over time, at least as part of shared bicycle programs.

In this article we examine the gender split in bicycle share trips made between 2014 and 2018 for three of the largest public bicycle share programs in the United States: Bluebikes (Boston), Citi Bike (New York), and Divvy Bikes (Chicago). We hypothesized that men would make more bicycle share trips than women, but that the gap would decrease over time.

\section{METHODS AND DATA}

\footnotetext{
* Simon Fraser University; Faculty of Health Sciences

Corresponding author email: khosford@sfu.ca

† Simon Fraser University; Faculty of Health Sciences
} 
We used publicly available system data provided by Bluebikes (formerly named Hubway prior to May 2018), Citi Bike, and Divvy Bikes for trips made between January 2014 and December 2018 (Bluebikes 2019; Citi Bike 2019; Divvy Bikes 2019). We selected these bicycle share programs because they had been operating for at least five years and included demographic information in their system data. To download the data, we used the $\mathrm{R}$ package bikedata (Padgham and Ellison 2017).

The system data includes a gender variable that indicates whether the trip was made by a man, woman, or is unknown, and an age variable for the birth year of the user. Gender and age data are typically only available for trips made by monthly and annual members because this information is collected when members sign up. However, there were trips made by casual users (single trip, $24 \mathrm{hr}, 3$-day) that also had demographic information. We excluded all trips for which gender was unknown from the final dataset.

We tabulated the number and proportion of annual and monthly bicycle share trips made by men and women from 2014 to 2018 for the three bicycle share programs. For the sub-sample of trips that also had information about age we examined the gender split by age category $(<25,25-34,35-44,45-54$, 55-64, 65+ years). With very large sample sizes (nearly 77 million trips) we focus on meaningful differences rather than statistical significance. Finally, to understand how the gender split in bicycle sharing compares to the gender split in bicycle commuting more generally, we retrieved gender-specific commute to work bicycle mode shares from the 2013-2017 ACS 5-year estimates for the areas that these bicycle share programs serve (U.S.Census Bureau 2017).

\section{FINDINGS}

A total of $89,057,337$ bicycle share trips were made across the three bicycle share programs between 2014 and 2018. Of these, 13.6\% were excluded because the gender of the user was unknown, leaving a total of $76,981,561$ trips. Excluded trips were predominantly made by casual users (92\%), where gender was less likely to be recorded. Trips retained in the analysis were predominantly made by annual and monthly members (98\%). Citi Bike accounted for over three-quarters of the trips ( 58.9 million), followed by Divvy Bikes (12.7 million) and Bluebikes (5.4 million). Of the 76,981,561 trips that had gender data, 76,058,835 (98.8\%) also had information about the user's age.

Overall, women made about one quarter of all bicycle share trips from 2014-2018, which is consistent across the three programs. Table 1 shows the gender breakdown of trips, overall and by year. Contrary to our hypothesis, with the exception of some movement for Citi Bike's program, there was remarkably little variation in the gender gap by program or year. The proportion of Citi Bike trips made by women increased steadily from $22.6 \%$ in 
Table 1: Count and Proportion of Bicycle Share Trips Made with Bluebikes, Citi Bike, and Divvy Bikes by gender, 2014-2018.

\begin{tabular}{|c|c|c|c|c|c|c|c|}
\hline & & \multicolumn{2}{|c|}{ Bluebikes } & \multicolumn{2}{|c|}{ Citi Bike } & \multicolumn{2}{|c|}{ Divvy Bikes } \\
\hline & & $\mathrm{n}$ trips & (\%) & $\mathrm{n}$ trips & (\%) & $\mathrm{n}$ trips & (\%) \\
\hline Overall & Men & $4,065,079$ & (74.7) & $44,409,806$ & (75.4) & $9,511,863$ & (75.0) \\
\hline 2014-18 & Women & $1,376,389$ & (25.3) & $14,450,452$ & (24.6) & $3,167,972$ & (25.0) \\
\hline \multirow[t]{2}{*}{2014} & Men & 687,659 & (74.7) & $5,635,962$ & (77.4) & $1,255,733$ & (75.5) \\
\hline & Women & 233,420 & (25.3) & $1,650,274$ & (22.6) & 407,621 & (24.5) \\
\hline \multirow[t]{2}{*}{2015} & Men & 649,687 & (74.0) & $6,608,929$ & (76.7) & $1,686,117$ & (74.8) \\
\hline & Women & 228,663 & (26.0) & $2,006,962$ & (23.3) & 567,351 & (25.2) \\
\hline \multirow[t]{2}{*}{2016} & Men & 755,177 & $(75.2)$ & $9,238,547$ & (75.6) & $2,047,174$ & (74.8) \\
\hline & Women & 248,737 & $(24.8)$ & $2,985,766$ & (24.4) & 689,780 & (25.2) \\
\hline \multirow[t]{2}{*}{2017} & Men & 830,821 & (75.7) & $10,955,046$ & (74.7) & $2,245,550$ & (75.0) \\
\hline & Women & 267,175 & (24.3) & $3,714,988$ & (25.3) & 746,637 & (25.0) \\
\hline \multirow[t]{2}{*}{2018} & Men & $1,141,735$ & (74.1) & $11,971,322$ & (74.5) & $2,277,289$ & (75.1) \\
\hline & Women & 398,394 & (25.9) & $4,092,462$ & (25.5) & 756,583 & (24.9) \\
\hline
\end{tabular}

2014 to $25.5 \%$ in $2018(+2.9 \%)$, a potentially meaningful change, whereas the proportion of trips made by women for the other two programs hovered steady around $25 \%$ over 2014 to 2018 .

While there was little variation in the bicycle share gender gap overall, it did vary by season and age. The proportion of trips made by women was lower in winter months compared to summer months (Figure 1). Across programs and years, women made $21.6 \%$ of all trips in peak winter months (November-February) compared to $26.0 \%$ of trips in summer months (June-August). The seasonal variation in the gender split was most prominent for Divvy Bikes, where women made $19.2 \%$ of trips in winter months and $27.4 \%$ of trips in summer months. In terms of age, the gender gap was generally wider for older bicycle share users (Table 2). For example, women accounted for upwards of $27 \%$ of trips made by users under the age of 35 years, but less than $20 \%$ of trips for users 65 years and older. The widest gender gap was for users of Bluebikes 65 years and older, where women made just $10.2 \%$ of all trips from 2015 to 2018. 
Table 2: Proportion of Bicycle Share Trips Made by Women with Bluebikes, Citi Bike, and Divvy Bikes by Age Category, 2014-18

\begin{tabular}{llll}
\hline & Bluebikes (2015-2018) & Citi Bike (2014-2018) & Divvy Bi \\
Age Category (Years) & of trips made by women in each age category & $30.6 \%$ & $28.7 \%$ \\
$<25$ & $27.0 \%$ & $27.6 \%$ & $27.2 \%$ \\
$25-34$ & $27.3 \%$ & $20.1 \%$ & $21.8 \%$ \\
$35-44$ & $21.2 \%$ & $20.9 \%$ & $22.0 \%$ \\
$45-54$ & $21.5 \%$ & $21.9 \%$ & $23.4 \%$ \\
$55-64$ & $26.1 \%$ & $14.9 \%$ & $18.2 \%$ \\
$65+$ & $10.2 \%$ & &
\end{tabular}

${ }^{a}$ Age stratified data was not available for Bluebikes in 2014 
Table 3 shows the proportion of commuters who regularly bicycle to work by gender. Across the areas these bicycle share programs serve, women make up over a quarter $(27.7-31.4 \%)$ of the commuters who report regularly bicycling to work while only accounting for a quarter of bicycle share trips. While some caution is needed when comparing bicycle share system data to the ACS data, given the former is about trips and the latter is people, our findings suggest that the gender gap in bicycle share use in these cities may be even wider than the gender gap in bicycle commuting overall. 
Table 3: Bicycle Commute Mode Shares in the Areas Serviced by Bluebikes, Citi Bike, and Divvy Bikes by Gender ${ }^{*}$ a

Geographies Served

Bluebikes

Citi Bike

Boston city, Brookline town, Cambridge city, Sommerville city

Divvy Bikes

Boroughs of Manhattan, Brooklyn and Queens, and Jersey City

Chicago city

"asource: US Census Bureau, 2013-2017 ACS 5-Year Estimates

$\mathrm{b} \%$ of commuters who regularly commute to work by bicycle
Total Workers

Commute to Work by Bicycle

505,988

$3,322,500$

$1,288,225$
17,195

44,930

21,391
Men

$\mathrm{n}(\%)^{\mathrm{b}}$

$11,790(68.6)$

$32,472(72.3)$

$15,246(71.3)$
Women

$\mathrm{n}(\%)^{\mathrm{b}}$

$5405(31.4)$

12,458 (27.7)

6145 (28.7) 

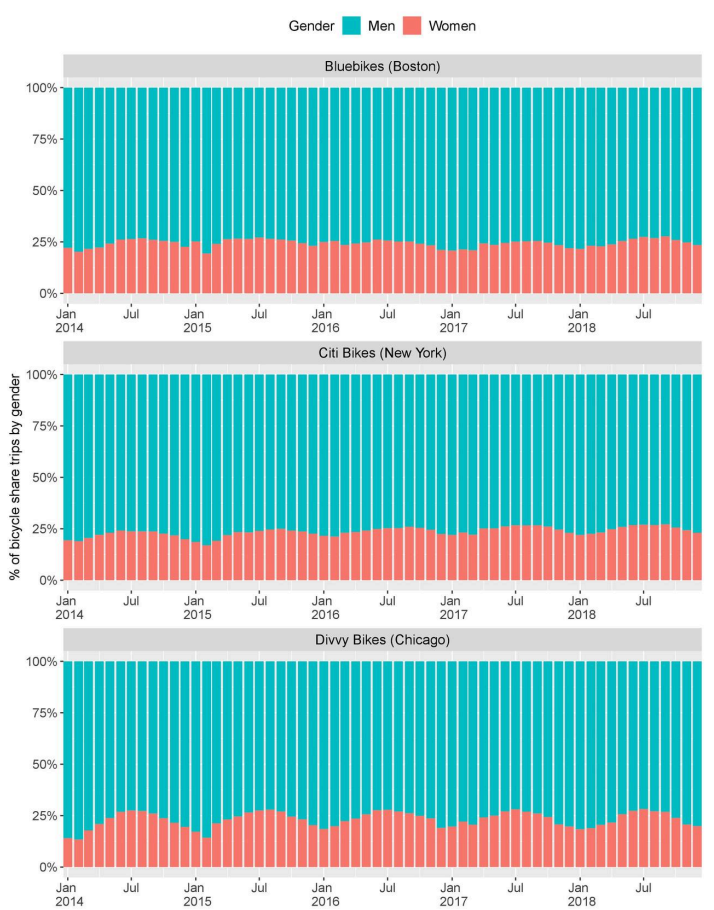

Figure 1. Proportion of Monthly Bicycle Share Trips Made with Bluebikes, Citi Bike, and Divvy Bikes by Gender, 2014-2018.

\section{ACKNOWLEDGMENTS}

We would like to thank Bluebikes, Citi Bike, and Divvy Bikes for making their system data publicly available. 


\section{REFERENCES}

Bluebikes. 2019. “System Data.” https://www.bluebikes.com/system-data.

Citi Bike. 2019. “System Data.” https://www.citibikenyc.com/system-data.

Dill, J., T. Goddard, C. Monsere, and N. McNeil. 2014. "Can Protected Bike Lanes Help Close the Gender Gap in Cycling? Lessons from Five Cities." Urban Studies and Planning Faculty

Publications and Presentations 123. https://pdxscholar.library.pdx.edu/usp.

Divvy Bikes. 2019. “Divvy Data.” https://www.divvybikes.com/system-data.

Goodman, A., J. Green, and J. Woodcock. 2014. "The Role of Bicycle Sharing Systems in Normalising the Image of Cycling: An Observational Study of London Cyclists." Journal of Transport $\mathcal{G}^{2}$ Health 1 (1): 5-8. https://doi.org/10.1016/j.jth.2013.07.001.

Padgham, Mark, and Richard Ellison. 2017. "Bikedata.” The Journal of Open Source Software 2 (20): 471. https://doi.org/10.21105/joss.00471.

Pucher, John, Ralph Buehler, Dafna Merom, and Adrian Bauman. 2011. "Walking and Cycling in the United States, 2001-2009: Evidence From the National Household Travel Surveys." American Journal of Public Health 101 (S1): S310-17. https://doi.org/10.2105/ajph.2010.300067.

Schoner, J., G. Lindsey, and D.M. Levinson. 2014. "Factors Associated with the Gender Gap in Bicycling Over Time.” http://hdl.handle.net/11299/179837.

Singleton, Patrick A., and Tara Goddard. 2016. "Cycling by Choice or Necessity?: Exploring the Gender Gap in Bicycling in Oregon." Transportation Research Record:Journal of the Transportation Research Board 2598 (1): 110-18. https://doi.org/10.3141/2598-13.

U.S.Census Bureau. 2017. "Commuting Characteristics by Sex. 2013-2017 American Community Survey 5-Year Estimates.” American FactFinder. http://factfinder.census.gov. 